\title{
Designing Personas with Empathy Map
}

\author{
Bruna Ferreira, Williamson Silva, Edson Oliveira, Tayana Conte \\ USES Research Group, Instituto de Computação - IComp \\ Universidade Federal do Amazonas (UFAM) \\ Manaus, AM - Brazil \\ \{bmf, williamson.silva, edson.cesar, tayana\}@icomp.ufam.edu.br
}

\begin{abstract}
A software product's acceptance depends on the user experience that it provides to its users. The software product must meet the user needs, and one way to understand those needs is through creation of Personas. The Personas technique allows describing the users' characteristics, goals and skills. The Empathy Map (EM) method can be used to describe personas. The EM's goal is to create a degree of empathy with the user so the product developing team starts to understand more deeply the users and become more aware of their real needs. To assess the EM effects on the creation of personas, we conducted a feasibility study with 20 subjects. Initially, the subjects learned how to describe personas in textual form. After that, they applied the EM to create personas. After using the EM, the subjects answered a questionnaire about their perceptions regarding the EM's ease of use and its usefulness. The results showed that majority of subjects considered EM useful and easy to create personas. Furthermore, this majority also said that they would use the EM for the creation of personas again.
\end{abstract}

\section{Keywords- Persona; Empathy Map; User Experience; $U X$.}

\section{INTRODUCTION}

The software development focuses on users' needs and emotions while interacting with the product is critical for the software product success [1]. According to Sproll et al. [1], as the field of User Experience (UX) explores these needs and their fulfillment, it gains in importance against the background of the wish for human-oriented products and services. In order to develop usable systems is necessary to understand the users that will interact with the system [2].

One technique that can be used to better understand the users' needs is the Personas technique. The Personas technique provides an understanding of the system user in terms of his or her characteristics, needs and goals to be able to design and implement a usable system [3]. The user modelling technique known as personas has obtained excellent results over the last years [4]. Furthermore, the Personas technique gathers data about users, gains and understanding of their characteristics, defines fictitious users (called personas) based on this understanding and focuses on these personas throughout the software development process [3]. Through the collected data using the Personas technique we can obtain greater knowledge of the user for which we are designing.

However, the creation of personas involves much creativity [5]. It is also difficult to verify if a persona really reflects user's data [5]. The Persona technique is used in order to aid designers to create empathy with the users and identify users' characteristics [2]. Empathy has been employed as a defining characteristic of designer-user relationships when design is concerned with user experience entails [6]. Furthermore, to guide designers to describe personas, we adopted the Empathy Map (EM). The EM is a method that helps designing business models based on the client perspectives [7]. The EM template has a visual organization. This organization simplifies the template implementation. Furthermore, the EM has guide questions [7]. This guide questions aid the designers during creation of personas, making this process more systematically.

This paper presents the results of a feasibility study where the EM is employed for the creation of personas. In this study, we evaluated the perception of the subjects regarding to ease of use and usefulness of the EM for the creation of personas. Through the analysis of the results it was possible to obtain the user's perception regarding the use of EM. In addition we identified improvement suggestions for the Empathy Map. The remainder of the paper is organized as follows. Section II presents the User Experience, Personas and Empathy Map concepts. Section III details the feasibility study, followed by our results in Section IV. The Section V shows the validity threats of the feasibility study. Finally, conclusions and comments on future work are given in Section VI.

\section{BACKGROUND}

\section{A. User Experience}

According to the ISO 9241 [8], User eXperience is defined as: "a person's perceptions and responses that result from the use and/or anticipated use of a product, system or service". The user experience explores how a person feels about using a product, i.e., the experiential, effective, meaningful and valuable aspects of product use [9]. The focus on the user's needs and emotions while interacting with a product is a key factor for the product success [1]. Therefore, user experience modeling is especially important for understanding, predicting and reasoning about UX processes, with implications for the software design [10]. One way to understand the user's needs is through the use of Personas.

\section{B. Personas}

Persona is a hypothetical archetype of a real user [12]. It describes the user's goals, skills and interests [12]. In order to describe personas, it is important to detail their characteristics, such as: name, image, occupation, family, friends and age [11]. Designers can choose various ways to represent personas, but they are usually represented in textual form, enriched by a photo. Among the benefits of using Personas, Cooper [12] cites: (1) it helps the development team to understand the 
characteristics of a group of users; (2) it proposes solutions related to the main users' needs; (3) it provides a human face to bring potential users closer to the team. The Persona technique is mainly criticized for being grounded in informal and unscientific data, for being difficult to implement, for not describing real people, and for preventing designers from contacting real users [13]. In summary, the usefulness and ease of use of the technique are often questioned.

\section{Empathy Map}

Empathy Map (EM) is a method that assists designing business models according to customer perspectives. It goes beyond demographic characteristics and develops a better understanding of the customer's environment, behavior, aspirations and concerns [7]. The EM's goal is to create a degree of empathy for a specific person [14]. According to Bratsberg [15], the EM is a user-centered approach, i.e., the focus is on understanding the other individual by looking at the world through his or her eyes. When the stakeholders understand the user, they are able to understand how small changes in design can have a big impact on users [15].

In the first version of the EM, Matthews [16], proposed four different areas that should be covered when making an Empathy Map of a person (see Fig. 1). After, Bland [16] improved the EM by including Pain and Gain areas. As a result, the EM consists of six areas: (a) See - what the user sees in his/her environment; (b) Say and Do - what the user says and how s/he behaves in public; (c) Think and Feel- what happens in the user's mind; (d) Hear -how the environment influences the user; (e) Pain- the frustrations, pitfalls and risks that the user experiences, and (f) Gain -what the user really wants and what can be done to achieve his/her goals. The EM also has a set of questions that guides how to fill the fields.

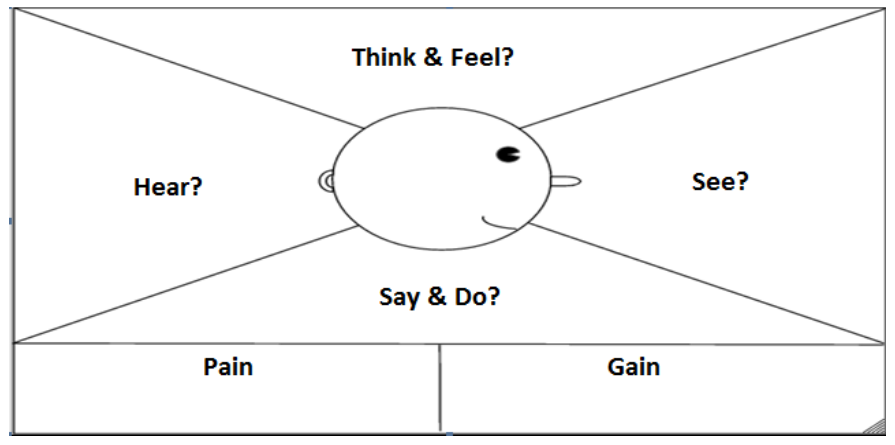

Figure 1. The Template of the Empathy Map [7].

\section{FEASIBILITY STUDY}

In order to verify the subject's opinion regarding the acceptance of the EM to create personas, we conducted a feasibility study with 20 volunteers' undergraduate and graduate students in Computer Science. In this study, the subjects should construct personas using both textual description and EM.

The subjects were attending a course on User Experience. All the 20 students agreed to participate in the feasibility study. We carried out the study in two days, during class time. In the first day, the subjects attended a class about the Personas technique. In order to create the personas, the subjects received scenarios to extract the personas' characteristics. We employed two scenarios. These scenarios are related to an application to assist persons with epilepsy. The application was being developed and the scenario was created according the application requirements. The application has two users: (1) persons with epilepsy and (2) family of persons with epilepsy. The first scenario described the routine of a person who has epilepsy. The second scenario described a routine of a family member of a person who has epilepsy. The first scenario was used for the creation of Personas through the text description. The second scenario was used to create Personas using the EM.

On the textual template, the subjects had to describe the following Persona features: (1) description of who the persona is (name, age, profession, gender, and others); (2) information on the persona's housing (where s/he lives, who s/he lives with, and other housing features); (3) what problems the persona faces; and (4) the persona's expectations, i.e., what the persona found or needed that could help to solve his/her problems. Besides describing the features, the subjects had to draw the created persona.

In the second day, we presented the EM template and explained how to use it. Then the subjects extracted information of the second scenario to describe the persona. In that context, the employed EM template was composed of the following fields: (1) do; (2) feel; (3) think; (4) pains (difficulties/ frustrations) and (5) needs.

Such template does not have the same fields that the original template. To simplify the template, we pulled the fields: 'see', 'say' and 'hear' because these fields referred to features related to the environment that the persona lives and not related to the persona. The fields: 'think' and 'feel', that are presented together in the original template, were separated to make the subjects think about the "think" (thoughts and ideas) and "feel" (emotions) aspects that can influence the user experience. Besides filling the fields, the subjects had to draw the persona as in the previous method. Fig. 2 presents the template used by subjects for creating the personas.

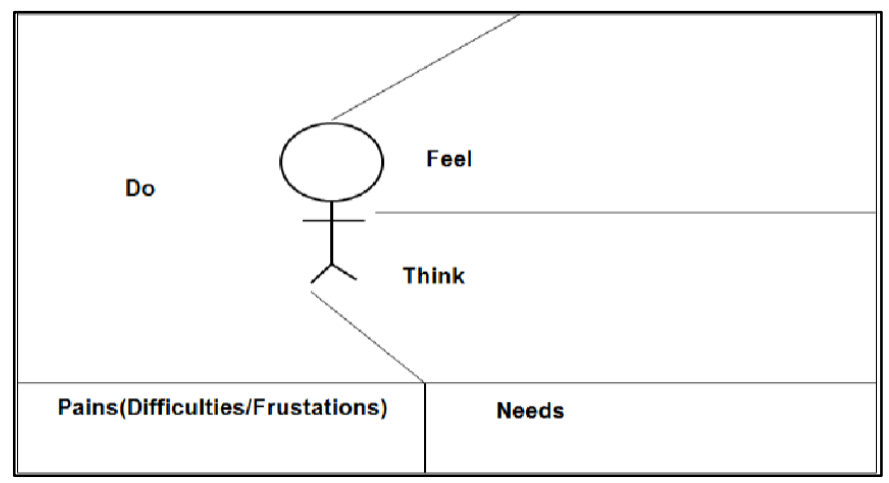

Figure 2. Empathy Map Template used in the study.

To fill the EM template, we provided some questions to help empathize with the persona; these questions are adapted from the original issues of EM. Each EM field had some specifics questions. These questions are described in Table I.

After the personas creation, the subjects answered a questionnaire giving their opinions regarding the use of the EM 
for the creation of personas. The subjects answered questions about the perceived ease of use and usefulness of the EM. Additionally, they answered questions regarding their intention of using the EM again and positives and negatives aspects of its application.

TABLE I. QUESTIONS FOR FILLING THE EMPATHY MAP [7]

\begin{tabular}{|c|c|}
\hline Field & $\begin{array}{r}\text { Guiding Questions } \\
\end{array}$ \\
\hline \multirow{12}{*}{ Do } & What is common for him / her to say? \\
\hline & How does s/he normally act? \\
\hline & What are his / her hobbies? \\
\hline & What does he like to say? \\
\hline & How is the world in which s/he lives? \\
\hline & What do people around him / her do? \\
\hline & Who are his / her friends? \\
\hline & What is popular in his daily life? \\
\hline & What people and ideas influence him / her? \\
\hline & What do the important people in his / her life say? \\
\hline & What are his / her favorite brands? \\
\hline & Who are his / her idols? \\
\hline Think & $\begin{array}{l}\text { What are some important ideas that s/he thinks and does } \\
\text { not say? }\end{array}$ \\
\hline \multirow{2}{*}{ Feel } & How does s/he feel about life? \\
\hline & What bothers him / her lately? Why? \\
\hline \multirow{4}{*}{$\begin{array}{c}\text { Pains } \\
\text { (Difficulties / } \\
\text { Frustrations) }\end{array}$} & What is s/he afraid of? \\
\hline & What are his / her frustrations? \\
\hline & What has disturbed him? \\
\hline & What would s/he like to change in his / her life? \\
\hline \multirow{5}{*}{ Needs } & What does s/he need to feel better? \\
\hline & What is success? What does s/he want to achieve? \\
\hline & What has s/he done to be happy? \\
\hline & What would end his / her pain? \\
\hline & What are some of his / her dreams? \\
\hline
\end{tabular}

In this study, we used factors defined within the Technology Acceptance Model (TAM), such as ease of use and usefulness [17] to investigate the subject's acceptance regarding the EM applied in the creation of personas. The TAM model is based on two factors [18]: Perceived Usefulness and Perceived Ease of use. On the questionnaire we employed a six points scale with the items: totally agree, strongly agree, partially agree, partially disagree, strongly disagree and totally disagree. We did not use an intermediate level as suggested by Laitenberger and Dreyer [18] since this neutral level does not provide information regarding the side to which the subjects are inclined (either positive or negative). In this questionnaire, the subjects answered a set of questions that measure the perceived usefulness and ease of use.

Besides the questions to be answered, we added three questions to the questionnaire to obtain more feedback about the subjects' perception regarding EM. The questions added to the questionnaire are presented in Table II.

TABLE II. SUBJECTIVE QUESTIONS ADDED IN THE QUESTIONNAIRE

\begin{tabular}{|c|l|}
\hline $\mathbf{N}^{\mathbf{0}}$ & \multicolumn{1}{c|}{ Question } \\
\hline 1 & $\begin{array}{l}\text { If you had to use personas again, would you choose the traditional } \\
\text { way or the Empathy Map? Why? }\end{array}$ \\
\hline 2 & $\begin{array}{l}\text { What aspects of the Empathy Map do you consider positive for the } \\
\text { creation of personas? }\end{array}$ \\
\hline 3 & $\begin{array}{l}\text { What aspects of the Empathy Map do you consider negative for the } \\
\text { creation of personas? }\end{array}$ \\
\hline
\end{tabular}

\section{RESULTS}

In this section, we describe the analysis of created personas generated by both methods. Furthermore, we describe the results regarding to the obtained answers from the subjects to the questionnaire.

\section{A. Perception about the Empathy Map's Usefulness}

Fig.3 shows the answers to each statement related to the perceived usefulness of the EM. Table III shows the factors evaluated in the perceived usefulness of EM.

TABLE III. STATEMENTS OF THE USEFULNESS

\begin{tabular}{|l|l|}
\hline ID & Statements \\
\hline U1 & Using EM would enable me to create Personas more quickly. \\
\hline U2 & Using EM would improve my performance when creating personas. \\
\hline U3 & Using EM would increase my productivity when creating personas. \\
\hline U4 & Using EM would enhance my effectiveness when creating personas. \\
\hline U5 & Using EM would make it easier to create personas. \\
\hline U6 & Using EM would be useful for creating personas in my projects. \\
\hline
\end{tabular}

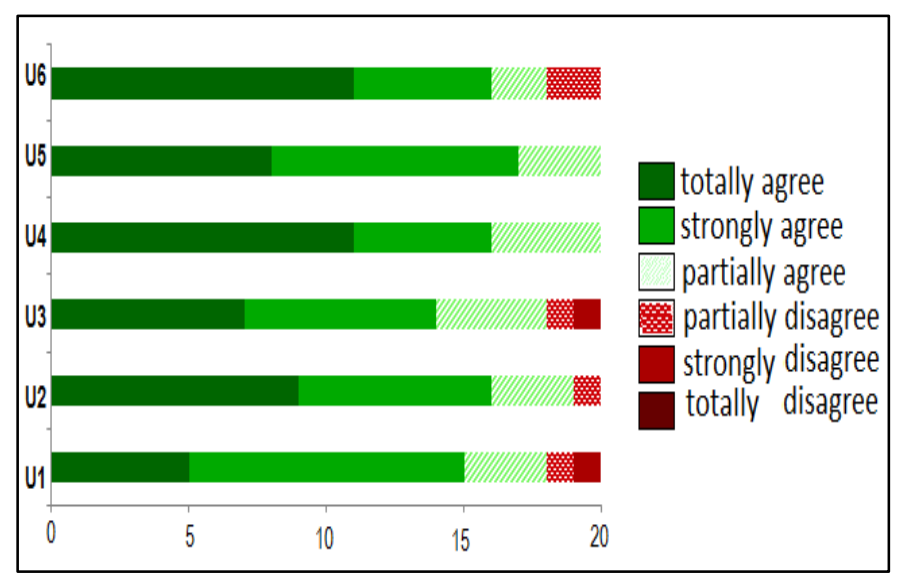

Figure 3. Results Regarding the Perceived Usefulness of EM

Regarding how quickly it was to create Personas using Empathy Map, only 02 out of 20 subjects disagreed that the EM helps creating Personas more quickly (U1). Regarding improved effectiveness on the creation of Personas (U4), i.e., to better describe the Persona using EM, no subject disagreed.

Regarding the performance in the creation of Personas (U2), i.e., being able to better characterize the persona using EM, only one subject disagreed. The subject that disagreed stated that the guiding questions were difficult to understand. Perhaps the difficulty in understanding had influenced subject's performance. All the 20 subjects agreed that the Empathy Map facilitated the creation of Personas (U5). Moreover, regarding productivity increase in the creation of Personas (U3), only two subjects disagreed. Finally, of the 20 subjects, 18 agreed that EM would be useful for creating Personas in their projects (U6). The results regarding usefulness showed that most of the subjects considered the EM useful for creating Personas.

\section{B. Perception about the Empathy Map's Ease of Use}

Fig.4 shows the answers regarding the perceived ease of use of the EM. Table IV shows the factors evaluated in the perceived ease of use of EM. 
TABLE IV. StATEMENTS OF THE EASE OF USE

\begin{tabular}{|l|l|}
\hline ID & Statements \\
\hline E1 & Learning how to works the EM would be easy for me. \\
\hline E2 & I understood what I had to provide in every part of the EM. \\
\hline E3 & It is easy to remember how to create personas using EM. \\
\hline E4 & Using EM it was easy to create the persona that I wanted. \\
\hline E5 & It was easy to become skillful in creating personas using EM. \\
\hline E6 & I find EM easy to use. \\
\hline
\end{tabular}

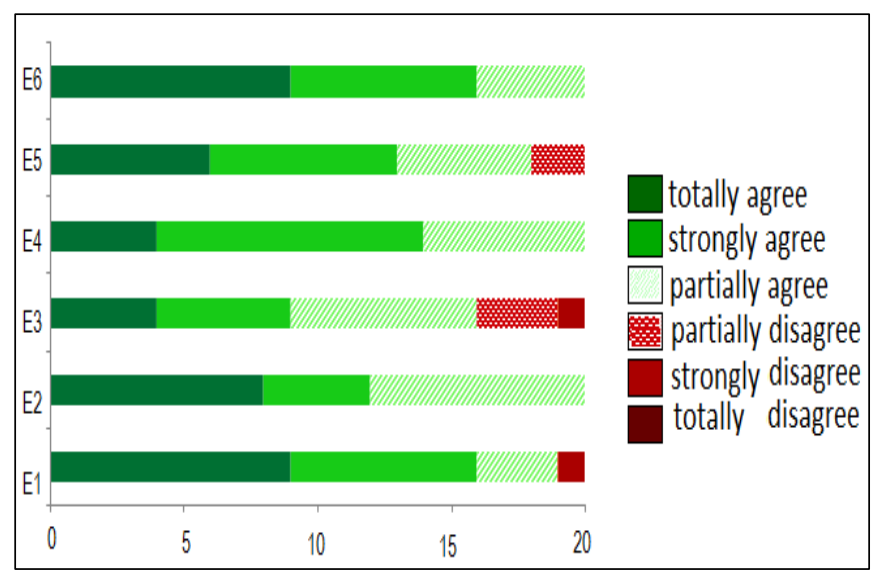

Figure 4. Results Regarding the Perceived Ease of Use of EM

Regarding the ease of learning to use the EM (E1), only one subject disagreed. All the subjects agreed that they were able to use the EM to create Personas as they wanted (E4). Regarding the understanding of the EM fields (E2), 4 out of the 20 subjects disagreed.

The difficulties in understanding, as well as other problems in the EM use will be discussed in the next subsection. All the subjects agreed that it was easy to gain the ability to use the EM (E5). From the 20 subjects, only 2 disagreed that is was easy to remember how to create Personas using EM (E3). All the subjects agreed that the Empathy Map was easy to use (E6).

\section{Qualitative Results}

Other way to investigate the point of view of subjects is to use qualitative methods. The use of qualitative methods allows the researcher to consider human behavior and thoroughly understand the studied object [19]. The qualitative analysis performed in this work is based on procedures from the Grounded Theory (GT) method. Grounded Theory is based on the coding idea that is the process of analyzing the data [20]. The Table $\mathrm{V}$ presents the results of the qualitative analysis.

TABLE V. RESULtS OF THE QUALITATIVE ANALYSIS

\begin{tabular}{|c|l|}
\hline Category & \multicolumn{1}{c|}{ Cotations } \\
\hline \multirow{2}{*}{$\begin{array}{c}\text { easiness in the } \\
\text { description of } \\
\text { personas }\end{array}$} & $\begin{array}{l}\text { EM is more flexible than the traditional approach. } \\
\text { 'The Empathy Map (...) facilitates, by providing the } \\
\text { and young a defined guide, but it is flexible } \\
\text { complete the description of the persona. - Subject 16 }\end{array}$ \\
\cline { 2 - 3 } & $\begin{array}{l}\text { EM guides inexperienced designers. } \\
\text { '...) I think that it (EM) can certainly be an initial } \\
\text { step for anyone who is learning to identify personas. '- } \\
\text { Subject 20 }\end{array}$ \\
\hline
\end{tabular}

\begin{tabular}{|c|c|}
\hline Category & Cotations \\
\hline & $\begin{array}{l}\text { The EM's fields guide the creation of personas. } \\
\text { 'The highly detailed description of the persona, the } \\
\text { way s/he acts, thinks, and his / her fears ... I believe } \\
\text { that categories help describe the personas.' - Subject } \\
12\end{array}$ \\
\hline & $\begin{array}{l}\text { EM deals with the subjective aspects of a persona. } \\
\text { '...it captures what the user 'feels' and 'thinks' which I } \\
\text { did not see in the traditional approach.'-Subject } 18\end{array}$ \\
\hline \multirow{5}{*}{$\begin{array}{l}\text { difficulties in } \\
\text { understanding } \\
\text { the EM }\end{array}$} & $\begin{array}{l}\text { Difficult to answer the guiding questions. } \\
\text { '...it is difficult to answer the questions used as a } \\
\text { guide, creating some uncertainty over where certain } \\
\text { descriptions fit, i.e., which would be the correct } \\
\text { quadrant'-Subject } 8\end{array}$ \\
\hline & $\begin{array}{l}\text { Questions seem to be similar for different fields on the } \\
\text { EM. } \\
\text { 'The questions seem similar in some categories and } \\
\text { can confuse at the moment of filling them.'-Subject } 3\end{array}$ \\
\hline & $\begin{array}{l}\text { Different fields of the EM appear to have the same } \\
\text { meaning. } \\
\text { '...the Empathy Map seems to confuse in some parts } \\
\text { that need to be filled. For instance, 'feel' and 'pain' } \\
\text { seem to be redundant' - Subject } 5\end{array}$ \\
\hline & $\begin{array}{l}\text { Confusion regarding on which field to fill in some } \\
\text { information (which generates duplicated information } \\
\text { in the persona). }\end{array}$ \\
\hline & $\begin{array}{l}\text { 'Sections 'needs' and 'pain' are very similar to the } \\
\text { section 'What do you think', which can generate } \\
\text { duplicated content'--Subject } 20\end{array}$ \\
\hline \multirow[b]{2}{*}{ limitations } & $\begin{array}{l}\text { The scenario influences the completeness of the } \\
\text { persona. } \\
\text { 'The completeness of the persona also depends on the } \\
\text { data available on the lifestyle, habits, among others.'- } \\
\text { Subject } 11\end{array}$ \\
\hline & $\begin{array}{l}\text { The structure of EM only helps if you have questions } \\
\text { guide. } \\
\text { 'Although the aspects of the map are clear (through } \\
\text { the words that define them), they leave each aspect } \\
\text { much broader. Without questions the answers (to fill } \\
\text { in the map) would certainly be very vague.' -Subject } 4\end{array}$ \\
\hline \multirow{4}{*}{$\begin{array}{l}\text { improvement } \\
\text { suggestions for } \\
\text { the EM }\end{array}$} & $\begin{array}{l}\text { Context field missing in the EM. } \\
\text { 'The lack of a context field <background }>\text { ' - Subject } \\
19\end{array}$ \\
\hline & $\begin{array}{l}\text { It should create a relationship between the personas. } \\
\text { '(...) in the case of personas that relate to others, } \\
\text { there could be an identified relationship with the other } \\
\text { personas'-Subject } 13\end{array}$ \\
\hline & $\begin{array}{l}\text { Guiding questions should be incorporated in the EM. } \\
\text { '(...) questions like a model could accompany the } \\
\text { process of creating the persona'-Subject } 16\end{array}$ \\
\hline & $\begin{array}{l}\text { More space for filling the fields in. } \\
\text { 'I believe that the template could be optimized, } \\
\text { providing larger space for some topics.' - Subject } 12\end{array}$ \\
\hline
\end{tabular}

In this subsection, we observed that the qualitative research helped us identify categories and relationships of factors that influence the use of the Empathy Map. 


\section{VALIDITY THREATS}

Every study possesses threats that can affect the validity of their results [21]. This subsection presents the threats to validity considered in this feasibility study. The textual form to create personas and the EM method had equivalent training. However, the results obtained through these methods cannot be directly compared because the scenarios used to create the personas were different. The scenario used to create the persona using the textual form was simple and it gave more details to persona creation. It was a basic scenario, in order to introduce the concept of personas to the subjects. Differently, the scenario to create personas using the EM was more elaborated. Furthermore, the textual form was used before the EM. This may have caused a learning effect. However, in this methodological approach, the subjects should understand the basic way to create personas before using the EM. Additionally, the level of education and knowledge of the subjects is also a validity threat.

\section{CONCLUSIONS}

This paper presented a feasibility study that aimed at verifying the subject's acceptance of the EM when employed in the creation of Personas. Based on the study's quantitative results, we perceived that most subjects think that the EM is easy to use and useful for the creation of personas. Through the qualitative analysis, we identified some features that are directly related to the use of the EM in the creation of personas. One of the results of the qualitative analysis showed that through the EM it is easy to describe personas. One of the reasons is that the EM provides more flexibility than the textual description. It also guides inexperienced practitioners through the creation process. We also observed that the guiding questions help subjects to fill the EM. We also found some limitations in the use of the EM for the creation of personas. Additionally, through the qualitative results, we identified some improvement suggestions for the EM.

According to results obtained from the qualitative and quantitative analysis, we observed that the EM method had a good acceptance. This method was considered easy to use and useful for the most of the subjects. Therefore, the results indicated that the EM is a good method to help the process of personas creation. The improvements identified on the qualitative results served as basis to we improve the EM template and make the method better to software engineer's use. Furthermore, we will also carry out a study in the industry. In such study, the EM will be employed by software engineers to help them design an application.

\section{ACKNOWLEDGMENT}

We thank all the students who participated in the feasibility study. And we would like to acknowledge the financial support granted by FAPEAM through processes numbers: 062.00146/2012; 062.00600/2014; 062.00578/2014; 01135/2011 and PAPE 004/2015.

\section{REFERENCES}

[1] S. Sproll, M. Peissner, C. Sturm, "From product concept to user experience: exploring UX potentials at early product stages" in 6th Nordic Conference on Human-Computer Interaction: Extending Boundaries. ACM, 2010. pp. 473-482, 2010.

[2] S. T. Acuña, J.W. Castro, N. Juristo, "A HCI technique for improving requirements elicitation," in Information and Software Technology, v. 54, n. 12, pp. 1357-1375, 2012.

[3] J. W. Castro, S. T. Acuña, N. Juristo, "Enriching requirements analysis with the personas technique," Proceedings of the Intl. Workshop on: Interplay between Usability Evaluation and Software Development (IUSED 2008). pp. 13-18, 2008.

[4] T. Ribeiro, P. Souza, "A Study on the use of personas as an usability evaluation method," in 16th International Conference on Enterprise Information Systems (ICEIS 2014), pp. 168-175, 2014.

[5] T. Matthews, T. Judge, S. Whittaker, "How do designers and user experience professionals actually perceive and use personas?," in Conf. on Human Factors in Computing Systems, pp. 1219-1228, 2012.

[6] P. Wright, J. Mccarthy, "Empathy and experience in HCI". in Conf. on Human Factors in Computing Systems. ACM.. pp. 637-646, 2008.

[7] A. Osterwalder, Y. Pigneur, "Business Model Generation", Alta Books, 2013.

[8] ISO 9241-210:2010. International Standardization Organization (ISO). Ergonomics of human system interaction -Part 210: Human-centred design for interactive systems. Switzerland, 2010.

[9] P. Vermeeren, C. Law, V. Roto, M. Obrist, J. Hoonhout \& K. VäänänenVainio-Mattila. "User experience evaluation methods: current state and development needs," in 6th Nordic Conference on Human-Computer Interaction: Extending Boundaries. ACM.. pp. 521-530, 2010.

[10] E. L. C. Law, S. Abrahão, A. P. Vermeeren, E.T. Hvannberg, "Interplay between user experience evaluation and system development: state of the art,". in Int. Workshop on the Interplay between User Experience (UX) Evaluation and System Development (I-UxSED 2012), pp. 1-3, 2012.

[11] J. Grudin, J. Pruitt, "Personas, participatory design and product development: An infrastructure for engagement," in: PDC. 2002. pp. 144-152, 2002

[12] A. Cooper, "The inmates are running the asylum:Why high-tech products drive us crazy and how to restorethe sanity," in Sams Publishers, 1999.

[13] L. Nielsen, K. S. Nielsen, J. Stage, J. Billestrup. 'Going global with personas.' International Conference on Human-Computer Interaction, INTERACT 2013. Springer Berlin Heidelberg, pp. 350-357, 2013

[14] D. Gray, S. Brown, J. Macanufo, "Gamestorming - A playbook for innovators, rulebreakers and changemakers," in Sebastopol, CA: O’Reilly Media, Inc., 2010.

[15] H. M. Bratsberg, "Empathy Maps of the FourSight Preferences," in Creative Studies Graduate Student Master's Project, Buffalo State College. Paper 176, 2012.

[16] D. Bland, "Agile coaching tip-What is an empathy map?," Available in http://www.bigvisible.com/2012/06/ what-is-an-empathy-map/, 2012.

[17] B. Langefors, "Discussion of the Article by Bostrom and Heinen: MIS Problems and Failures: A Socio-Technical Perspective. Part I: The Causes [MIS Quarterly, September 1977]. 1978.

[18] O. Laitenberger, H. M. Dreyer, "Evaluating the usefulness and the ease of use of a web-based section data collection tool," In 5th International Symposium on Software Metrics, pp.122-132, 1988.

[19] C. B. Seaman, "Qualitative Methods". In: Guide to Advanced Empirical Software Engineering (Shull et al.. (eds.): Springer., pp. 35 - 62, 2008.

[20] A. Strauss, J. Corbin, "Basics of Qualitative Research: Techniques and Procedures for Developing Grounded Theory," in Thousand Oaks, CA, SAGE publications, 2014.

[21] C. Wohlin, P. Runeson, M. Host, M. C. Ohlsson, B. Regnell, and A. essl, "Experimentation in Software Engineering: An Introduction", Kluwer Academic Publishers, 2000. 